\title{
The Accidental Tide Gauge: A GPS Reflection Case Study From Kachemak Bay, Alaska
}

\author{
Kristine M. Larson, Richard D. Ray, Felipe G. Nievinski, and Jeffrey T. Freymueller
}

\begin{abstract}
For the last decade, it has been known that reflected GPS signals observed with specialized instruments could be used to measure sea level. In this letter, data from an existing geodeticquality GPS site near Kachemak Bay, Alaska, are analyzed for a one-year time period. Daily sea-level variations are more than $7 \mathrm{~m}$. Tidal coefficients have been estimated and compared with coefficients estimated from records from a traditional tide gauge at Seldovia Harbor, $\sim 30 \mathrm{~km}$ away. The GPS and Seldovia estimates of $M_{2}$ and $S_{2}$ coefficients agree to better than $2 \%$; much of this residual can be attributed to true differences in the tide over $30 \mathrm{~km}$ as it propagates up Kachemak Bay. For daily mean sea levels the agreement is $2.3 \mathrm{~cm}$. Because a standard geodetic GPS receiver/antenna is used, this GPS instrument can measure long-term sea-level changes in a stable terrestrial reference frame.
\end{abstract}

Index Terms-GPS, multipath, reflections, tide gauge.

\section{INTRODUCTION}

$\mathbf{T}$ HE TECHNOLOGY for measuring sea level at a coastal site is well established. We are nearing almost two centuries of experience with self-recording tide gauges, with the most common one consisting of a float isolated from highfrequency wave motion by a stilling well [1], but acoustic, pressure, or microwave-based systems are also now in use [2], [3]. The conventional tide gauge measures relative sea levels, i.e., relative to benchmarks on the adjoining land, which is the quantity of interest for most applications such as navigation and coastal flooding. Other applications, particularly estimating changes in the global ocean volume and related aspects of the global sea-level budget, require absolute sea-level measurements, i.e., relative to the geocenter or to a fixed terrestrial reference frame [4], [5]. Effects such as glacial isostatic adjustment, coseismic and postseismic deformation, and land subsidence make it challenging to use conventional tide gauges to measure absolute sea level. These kinds of "local" ground motion at tidegauge stations can, however, be measured with continuously operating GPS receivers, and the resulting information can be used to convert between relative and absolute sea levels.

Manuscript received October 8, 2012; accepted November 24, 2012. This work was supported in part by AGS0935725 and EAR0948957.

K. M. Larson and F. G. Nievinski are with the Department of Aerospace Engineering Sciences, University of Colorado, Boulder, CO 80309 USA (e-mail: kristinem.larson@gmail.com; fgnievinski@gmail.com).

R. D. Ray is with National Aeronautics and Space Administration (NASA) Goddard Space Flight Center, Greenbelt, MD 20771 USA (e-mail: richard.ray@nasa.gov).

J. T. Freymueller is with the University of Alaska, Fairbanks, AK 99775 USA (e-mail: jeff.freymueller@gi.alaska.edu).

Color versions of one or more of the figures in this paper are available online at http://ieeexplore.ieee.org.

Digital Object Identifier 10.1109/LGRS.2012.2236075
The critical need for such land-motion information has led to an international campaign to deploy GPS receivers (and other geodetic systems) at a wide array of globally distributed tide gauges [6], [7].

It was recently demonstrated that geodetic-quality GPS instruments installed to measure crustal deformation, but sited very near the coast, could be used to measure sea level directly and without local ground motion errors [8]. In this experimental setup, power measurements made by the receiver are used to deduce the distance between the GPS antenna and the sea, which is relative sea level, yet the GPS station also provides, by design, the data necessary for placing those estimated sea levels into a true terrestrial reference frame, i.e., into absolute sea level. This is distinct from previous GPS reflection studies that used either specialized instruments or installations (see, e.g., [9], [10], and references therein).

In this letter, we examine a one-year data set from a challenging GPS site in Kachemak Bay, Alaska. Tidal variations at this site are among the largest in the United States. We are able to estimate both high- and low-frequency sea-level variations, which can be compared with similar signals from a nearby conventional tide gauge. The large tidal variations present some new additional challenges for deducing sea level from GPS reflections, a topic discussed in detail in the next section. These data sets present a unique opportunity to investigate such measurements in a challenging, and clearly macrotidal, environment.

\section{GPS DATA}

The GPS site at Peterson Bay (PBAY) is located on a small rocky island on the south side of Kachemak Bay, in the Cook Inlet of Alaska (see Fig. 1). Due to the dense vegetation cover of most of the region, only small rocky islands remain free of trees and thus have suitable sky view for GPS observations. PBAY was installed by the University of Alaska Fairbanks as part of a project to better understand crustal deformation in the area surrounding Kachemak Bay (see Fig. 1 and Appendix). The unit provides coverage of the south side of the bay, which has bedrock at the surface, to ensure that one could detect any contrast with the north side of the bay, which has sediments at the surface.

Reflected GPS signals (multipath) are one of the major error sources in crustal deformation studies, where the objective is to measure the position of the GPS antenna phase center. Multipath effects measured by geodetic-quality GPS instruments can also be used to accurately measure environmental signals (see [8] and references therein). A defining feature of these 


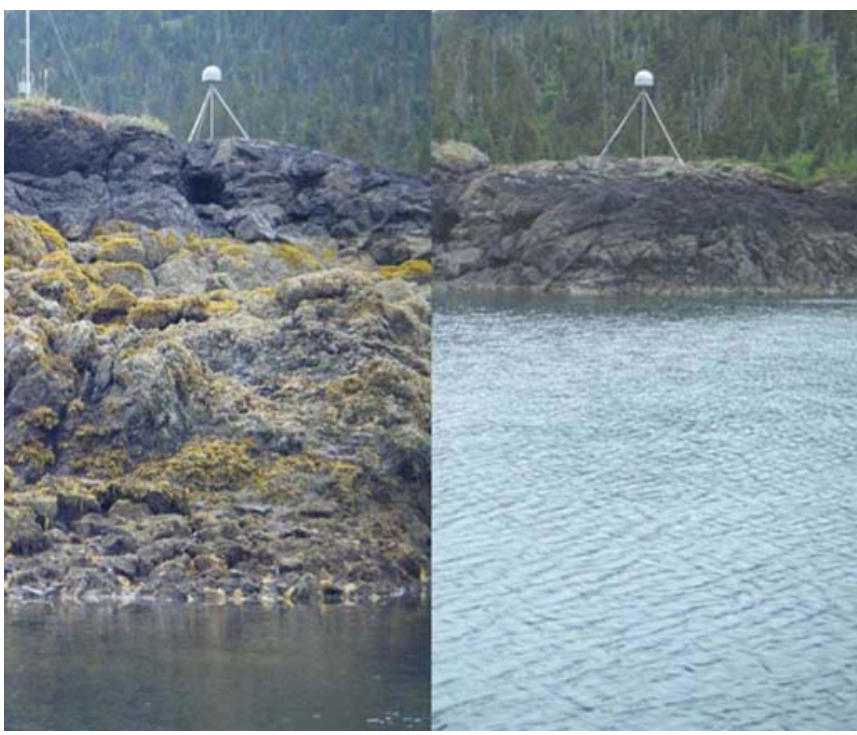

Fig. 1. Photograph of PBAY GPS site at low and high tides.

multipath studies is the use of signal-to-noise ratio (SNR) data instead of the carrier phase data used for positioning. SNR data are dominated by long-period variations due to the receiver-satellite distance and the gain pattern of the antenna. If these long-period variations at low elevation angles $\left(<30^{\circ}\right)$ are removed with a low-order polynomial, one is left with only the multipath effect.

For a horizontal planar surface, the model for GPS multipath is straightforward. The multipath effect is driven by the instantaneous excess propagation delay $d$ of a reflection with respect to the direct path

$$
d=2 H \sin e .
$$

$H$ is the height of the antenna above the reflecting surface (or reflector height) and $e$ is the elevation angle of the satellite with respect to the horizon [11]. When the surface is stationary, the instantaneous phase $\phi=k d$ (where $k=2 \pi / \lambda$ is the wavenumber and $\lambda$ is the GPS carrier wavelength) is driven by a constant factor of $4 \pi H / \lambda$ times the variable sine [11]. Since GPS multipath measures the distance between the antenna and the reflecting surface, the highest water levels produce the smallest reflector heights and the lowest modulation frequencies. Fig. 1 shows representative SNR data from the PBAY site. The SNR data clearly show significantly different multipath frequencies; these are anticorrelated with sea-level heights measured by a tide gauge.

If $H$ is constant, spectral analysis of SNR data with $\sin e$ as the independent argument yields a peak whose frequency is linearly related to $H$. However, this model is not accurate enough for the PBAY data where a new model appropriate for a moving planar surface is required. We start with the derivative of $d$ with respect to time

$$
\dot{d}=2 H \dot{e} \cos e+2 \dot{H} \sin e .
$$

Equation (2) can be interpreted as the sum of a dynamic satellite term and a dynamic surface term [12]. An angular delay rate can

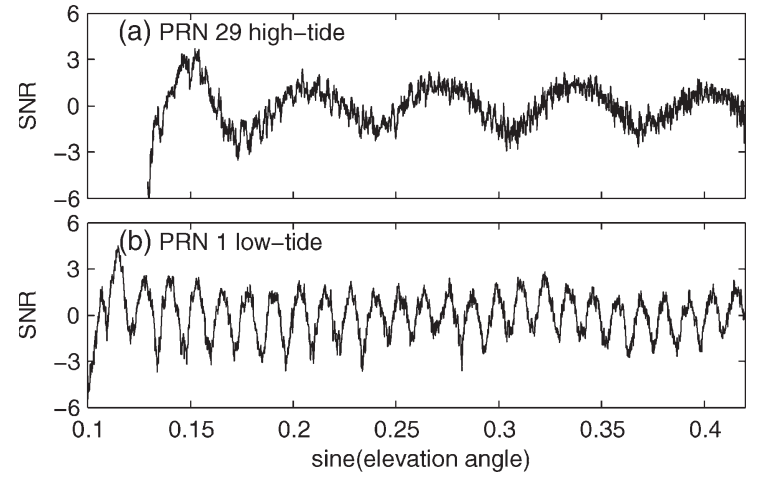

Fig. 2. GPS SNR data (converted from $\mathrm{dB}-\mathrm{Hz}$ to volts/volts and detrended) for two GPS satellite tracks at high and low tides.

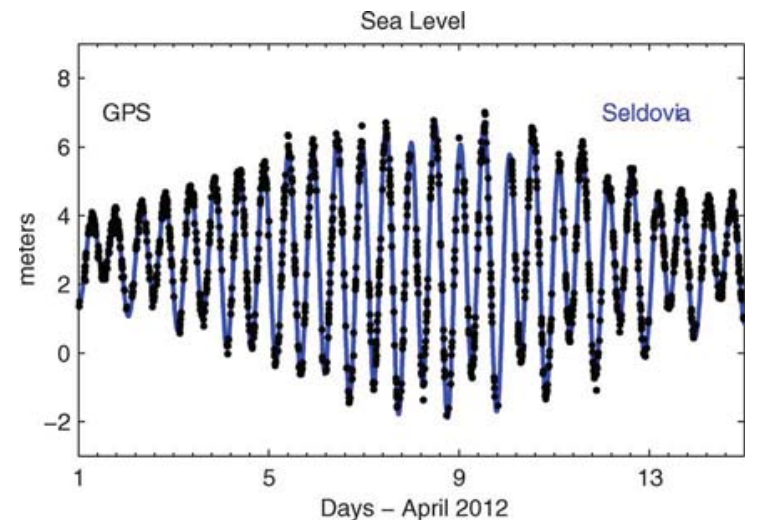

Fig. 3. Time series of sea-level estimates from (circles) GPS and (line) tidegauge data for Seldovia.

then be defined

$$
\stackrel{\circ}{d}=\frac{\partial d}{\partial \sin e}=\frac{\partial d}{\partial t} / \frac{\partial \sin e}{\partial t}=\frac{\dot{d}}{\dot{e} \cos e}
$$

or

$$
\stackrel{\circ}{d}=2 H+2 \dot{H} \tan e / \dot{e} .
$$

The first term on the right-hand side of (4) is the usual result for stationary surfaces discussed earlier, and the second term is a height-rate correction to the otherwise biased spectral peak height.

We solve for the two unknowns iteratively. We first estimate $H$ values with a Lomb-Scargle periodogram to obtain a preliminary height time series. We then estimate $\dot{H}$ and calculate $\tan e / \dot{e}$ values to produce height corrections (see Fig. 2 and Appendix). These are removed from the preliminary time series, resulting in a final height time series (see Fig. 3).

GPS data collected between June 26, 2011 and June 30, 2012 were analyzed. The locations of the transmitting satellites were computed using the broadcast ephemeris; these are subsequently used to compute the local azimuth and elevation angle (and its rate of change) of the satellite with respect to the GPS receiver. A total of 39 rising or setting GPS satellite tracks were used. Minimum and maximum elevation cutoffs were set to $5^{\circ}$ and $25^{\circ}$. Above $25^{\circ}$, the multipath signature is small, and the reflecting region (Fresnel zone) often includes both land and water (see Fig. 3 and Appendix). The reflecting region varies 
with elevation angle and reflector height, but in general, each track provides an average over thousands of square meters. For this particular site, an azimuth mask of $90^{\circ}$ to $260^{\circ}$ was imposed. This mask removed reflections that are impacted by the trees behind the GPS antenna.

In order to report a reflector height, we required the use of 800 SNR measurements $(\sim 14 \mathrm{~min})$, a normalized spectrogram peak of $1 \mathrm{~dB}-\mathrm{Hz}$, and a peak-to-noise ratio greater than 3. "Nonphysical" reflector height peaks were discarded, i.e., reflector heights greater than $11 \mathrm{~m}$ or less than $3 \mathrm{~m}$. After these quality control measures were imposed, $\sim 80$ sea-level retrievals were produced per day. However, it must be emphasized that these retrievals are not evenly spaced in time as they would be for a dedicated tide gauge.

\section{Discussion}

The definitive test of the GPS-based sea level estimates is comparison with measurements made with standard tide gauges. As there is no exactly collocated tide gauge at the PBAY site, some allowance must be made for small, but real, ocean differences between sites. At the Seldovia tide-gauge site (30 km distant), a long multidecade time series of hourly sealevel data is available, including data concurrent with our GPS data. There are also a handful of other historical gauges in Kachemak Bay; their time series are all very short ( 29 d), but they are still useful for delineating general tidal characteristics within the bay.

It is most useful to separate the comparisons into two regimes: low frequency and high frequency (once/day and higher). The high-frequency comparisons could be done with (for example) 6-min or hourly measurements, once the GPS estimates have been appropriately processed and resampled. The high-frequency regime, however, is so dominated by large tidal signals, and the corresponding sea-level differences are likely dominated by small changes in the real tide between stations that it seems preferable to estimate and compare the tidal components directly. Moreover, since the low-frequency signals are best derived from the tidal residuals, we begin with an analysis of the tidal signals.

\section{Comparison to Tide-Gauge Data: Tidal Regime}

A regional picture of tides covering Lower Cook Inlet and the adjoining Gulf of Alaska is shown in Fig. 4 in terms of cotidal charts for the largest semidurnal $\left(M_{2}\right)$ and diurnal $\left(K_{1}\right)$ constituents. These charts are based on data that we have extracted from a North Pacific finite-element numerical tide model [13]. The semidiurnal $M_{2}$ is seen to gain in amplitude after entering Cook Inlet, exceeding $200 \mathrm{~cm}$ at the mouth of Kachemak Bay. The diurnal $K_{1}$ also grows in amplitude, although more weakly. While the charts of Fig. 4 give a useful regional view, the resolution of the finite-element model in Kachemak Bay is probably too coarse (approximately $4 \mathrm{~km}$ ) to give reliable results in the bay itself, particularly in the upper bay. The model does suggest that $K_{1}$ is fairly constant within Kachemak Bay and that Seldovia and PBAY diurnal tides might be comparable. It also suggests, however, that the semidiurnal tides may differ by several centimeters or more.
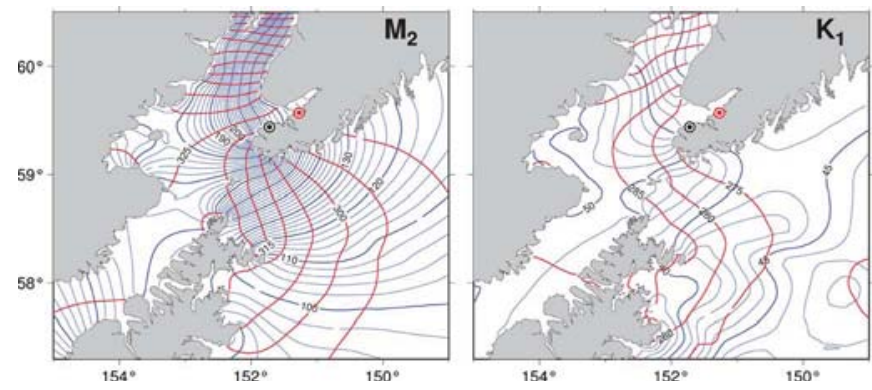

Fig. 4. Cotidal charts of the (left) M2 and (right) K1 tidal coefficients from [13]. Amplitudes (in centimeters) are in blue. Greenwich phase lags are in red. Black and red circles denote locations of Seldovia and the PBAY GPS site, respectively.

This regional picture of Kachemak Bay tides is generally confirmed by historical tide data within the bay proper. Space precludes a detailed comparison, but they confirm a pattern of nearly constant diurnal amplitudes and phases within Kachemak Bay. The semidiurnal $M_{2}$ amplitudes increase by $7 \mathrm{~cm}$ from Seldovia to the head of the bay, as do $S_{2}$ amplitudes. This suggests that the tides at PBAY and Seldovia may differ by several centimeters in both $M_{2}$ and $S_{2}$, with PBAY being larger and only slightly lagged, while the diurnal tides may be expected to be very close.

Based on the Seldovia tide-gauge spectrum, we estimated a total of 91 constituents by least squares harmonic analysis. The analysis included standard adjustments for nodal and perigee modulations of lunar constituents [14]. The variance of the residual time series after tidal analysis at Seldovia is $198 \mathrm{~cm}^{2}$. At PBAY, the residual variance is $386 \mathrm{~cm}^{2}$, indicative of higher noise in the individual GPS sea-level estimates. For the GPS tidal estimates, the standard errors were computed from the standard deviations of 12 monthly subset solutions, scaling by $12^{-1 / 2}$. (Since $P_{1}$ and $K_{2}$ are unresolved in monthly analyses, their standard errors are simply set to those of $O_{1}$ and $S_{2}$, respectively.) These errors are understandably much larger than those for the long Seldovia time series but are much less than $1 \mathrm{~cm}$ for even the largest constituents.

Table I presents a summary compilation of the estimated tides. In it are included all diurnal and semidiurnal constituents of amplitude $7 \mathrm{~cm}$ or greater and all higher order compound tides of amplitude $1 \mathrm{~cm}$ or greater. Standard errors are also included.

Long-period tidal constituents were also computed but are purposely not included in the table to prevent readers from thinking they might be legitimate estimates. Only a long multiyear time series can provide reliable estimates, and even then, they typically have large uncertainties. An analysis of one year of Seldovia gauge data, corresponding to the same time as the GPS series, yields reasonably good agreement at the long-period tidal frequencies, the largest being the annual with $(H, G)=\left(6.8 \mathrm{~cm}, 227^{\circ}\right)$ for the GPS and $\left(7.4 \mathrm{~cm}, 233^{\circ}\right)$ at Seldovia. The long-term mean of the annual constituent at Seldovia is $\left(12.7 \mathrm{~cm}, 256^{\circ}\right)$.

A few aspects of Table I are immediately noteworthy. The three largest semidiurnal tides are slightly larger in the GPS than the Seldovia gauge, and with greater phase lags, and this surely owes to real ocean differences between the sites 
TABLE I

Amplitude H, Phase LAG G, AND Standard

ERROR OF SELECTED TIDAL COEFFICIENTS

\begin{tabular}{|c|c|c|c|c|c|c|}
\hline \multirow{3}{*}{ Tide } & \multicolumn{3}{|c|}{ Seldovia gauge } & \multicolumn{3}{|c|}{ Peterson Bay GPS } \\
\cline { 2 - 7 } & $\begin{array}{c}H \\
(\mathrm{~cm})\end{array}$ & $\begin{array}{c}G \\
(\mathrm{deg})\end{array}$ & $\begin{array}{c}\sigma \\
(\mathrm{cm})\end{array}$ & $\begin{array}{c}H \\
(\mathrm{~cm})\end{array}$ & $\begin{array}{c}G \\
(\mathrm{deg})\end{array}$ & $\begin{array}{c}\sigma \\
(\mathrm{cm})\end{array}$ \\
\hline $\mathrm{O}_{1}$ & 34.33 & 263.71 & 0.04 & 33.54 & 264.2 & 0.42 \\
\hline $\mathrm{P}_{1}$ & 17.62 & 277.90 & 0.04 & 17.26 & 278.7 & 0.42 \\
\hline $\mathrm{K}_{1}$ & 56.10 & 279.76 & 0.05 & 54.63 & 278.7 & 0.53 \\
\hline$\mu_{2}$ & 8.90 & 276.81 & 0.07 & 8.57 & 272.8 & 0.47 \\
\hline $\mathrm{N}_{2}$ & 46.37 & 298.16 & 0.15 & 47.31 & 299.0 & 0.47 \\
\hline$v_{2}$ & 7.62 & 301.77 & 0.10 & 7.60 & 301.2 & 0.47 \\
\hline $\mathrm{M}_{2}$ & 222.27 & 324.04 & 0.16 & 225.43 & 324.7 & 0.71 \\
\hline $\mathrm{S}_{2}$ & 82.90 & 358.25 & 0.08 & 83.88 & 359.1 & 0.72 \\
\hline $\mathrm{K}_{2}$ & 22.63 & 350.89 & 0.07 & 22.34 & 352.5 & 0.72 \\
\hline $\mathrm{MO}_{3}$ & 2.78 & 183.21 & 0.04 & 2.88 & 192.8 & 0.36 \\
\hline $\mathrm{SO}_{3}$ & 1.37 & 209.07 & 0.03 & 1.31 & 211.1 & 0.41 \\
\hline $\mathrm{MK}_{3}$ & 1.88 & 201.86 & 0.03 & 2.10 & 202.9 & 0.41 \\
\hline $\mathrm{MN}_{4}$ & 1.09 & 40.47 & 0.02 & 1.48 & 45.4 & 0.28 \\
\hline $\mathrm{M}_{4}$ & 3.04 & 69.16 & 0.03 & 3.93 & 76.5 & 0.28 \\
\hline $\mathrm{MS}_{4}$ & 2.56 & 116.00 & 0.02 & 3.51 & 120.0 & 0.48 \\
\hline $\mathrm{M}_{6}$ & 1.56 & 195.77 & 0.02 & 1.93 & 201.1 & 0.16 \\
\hline $2 \mathrm{MS}_{6}$ & 1.45 & 240.21 & 0.03 & 1.79 & 249.7 & 0.28 \\
\hline
\end{tabular}

as suggested by Fig. 4. The smaller semidiurnals agree to within their standard errors, except for (the partly nonlinear) $\mu_{2}$, which displays a slightly larger difference. The largest vector difference is $4.1 \mathrm{~cm}$, for $M_{2}$, but this is only $1.8 \%$ of the large $M_{2}$ amplitude. $S_{2}$ differs similarly by $1.9 \%$. The difference of $4.1 \mathrm{~cm}$ in $M_{2}$ is consistent with what might be inferred from Fig. 4 and the historical gauge data.

A noteworthy feature of the much smaller compound tides is that every one shows a larger phase lag at PBAY than at Seldovia. Every one, save $\mathrm{SO}_{3}$, also shows larger amplitude at PBAY. We have no knowledge concerning the generation regions for compound tides in the Lower Cook Inlet, but the consistent amplitude and phase differences suggest true tide differences at our two locations, with possible wave propagation into the bay from the west.

The case of $K_{1}$ is of special interest because its period is exactly 1 sidereal day, so it is very nearly locked to the GPS satellite sampling period. Thus, the $K_{1}$ frequency can become corrupted by any number of errors related to GPS sampling, particularly orbit errors [15]. $K_{2}$, locked to half the GPS sampling period, can be similarly corrupted. Our results for $K_{1}$ are far from poor and, in fact, are reasonably good with a vector difference of $1.8 \mathrm{~cm}$, but they do appear slightly anomalous. The difference of $1.8 \mathrm{~cm}$ is much larger than corresponding differences for the other diurnals $O_{1}$ and $P_{1}$. Moreover, the estimated amplitude of $K_{1}, 54.6 \pm 0.5 \mathrm{~cm}$, is smaller than the amplitudes at all the historical stations (not shown), which are between 56.1 and $57.2 \mathrm{~cm}$. Our GPS estimate may thus be in error by $1-2 \mathrm{~cm}$.

Not included in Table I is $S_{1}$, of period of exactly $24.0 \mathrm{~h}$. $S_{1}$ is generally a very small tide [16] but of special interest in testing new measurement systems because it is often associated with thermal errors in instrumentation owing to the daily heating and cooling cycle. To compare $S_{1}$ solutions, we use our estimates for Seldovia that correspond to the same one-year interval as the GPS data. For the tide-gauge data, we obtain $(H, G)=\left(1.41 \mathrm{~cm}, 72.9^{\circ}\right)$; for the GPS, we obtain $(1.65 \mathrm{~cm}$,

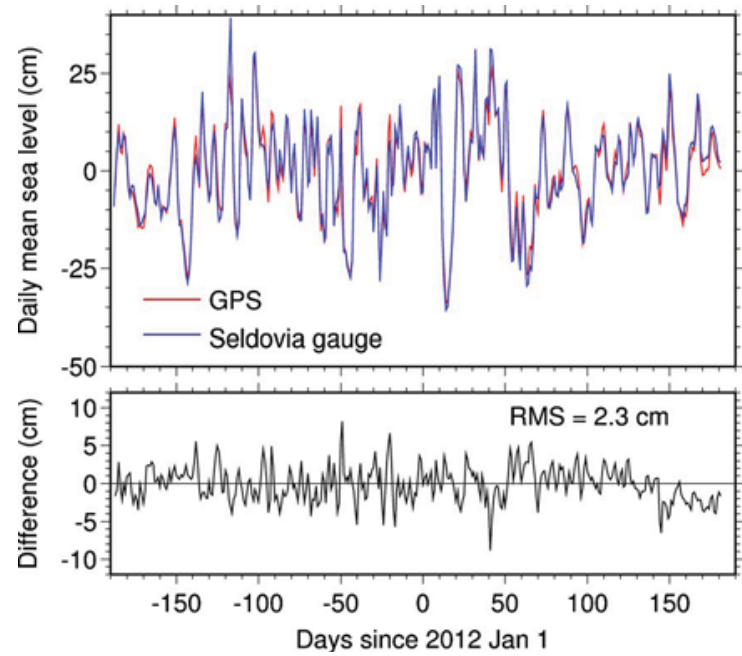

Fig. 5. (Top) Daily mean sea levels from the Seldovia tide gauge and PBAY. (Bottom) Differences between the top-panel curves.

$74.9^{\circ}$ ), with a vector difference of only $0.24 \mathrm{~cm}$. Since part of this difference could again stem from real ocean differences at the sites, we conclude that any errors associated with daily thermal or radiational effects must be very small in both systems.

In summary, this analysis of the tidal signals suggests that the GPS-based tide estimates appear very reliable and that most of the discrepancies with the tide gauge at Seldovia can be attributed to real ocean-tide differences between the two sites.

\section{Comparison to Tide-Gauge Data: Low-Frequency Regime}

In this section, our goal is to quantify the level of daily differences and to determine whether any long-term trends are evident in the two time series. The Seldovia gauge data used in this section are daily means computed using procedures identical to those used by the University of Hawaii Sea Level Center. This is done by removing a predicted tide from hourly data, applying an antialiasing low-pass filter, and computing means for each 24-h segment.

We followed a similar procedure with the GPS time series, except for an initial step needed to first form a time series of hourly means. This was done from the original unequally sampled sea-level estimates by removing a predicted tidal signal based on coefficients as in Table I and then applying a Savitzky-Golay filter of full width $2.4 \mathrm{~h}$. These filtered tidal residuals were then binned into hourly means, and subsequently, the same procedures as used for the gauge data were applied. The one nonstandard aspect of our processing is that we have removed from each data set the long-period, as well as the short-period, tides; this was done because of small observed differences in the long-period tides at the two locations.

Fig. 5 shows daily mean sea levels for both stations, as well as their differences; the rms difference is $2.3 \mathrm{~cm}$. There is no hint of any long-period offsets or trends in the differences. As before, it is possible that some part of this $2.3 \mathrm{~cm}$ owes to true ocean differences at the two sites, for example, from differences in wind setup. Although we removed long-period tides separately from each time series, including annual and semiannual components, which will act to reduce site differences, 

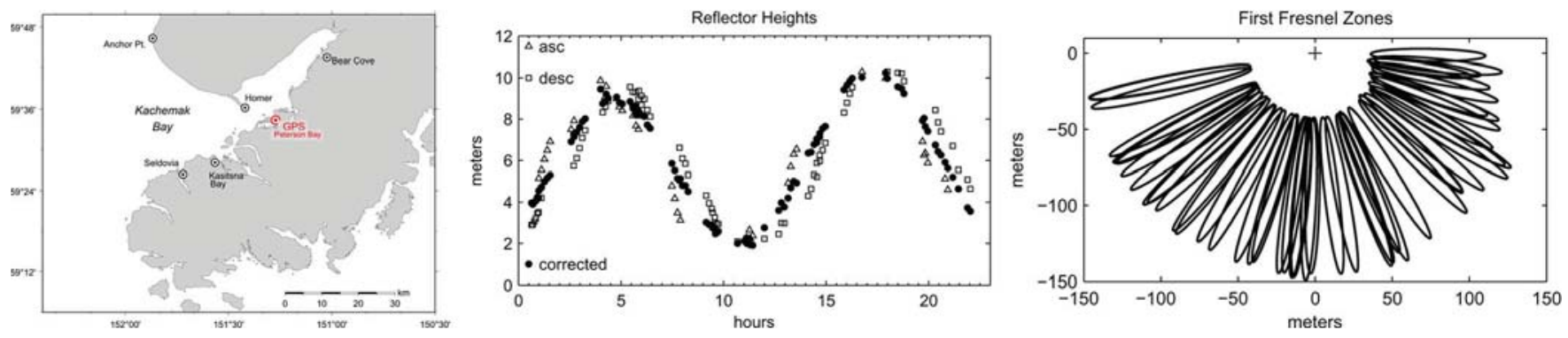

Fig. 6. Supplemental images for Fig. 1 (left), Fig. 2 (middle), and Fig. 3 (right). See also http://ieeexplore.iee.org.

small differences at nontidal periods could remain. We can conclude that the GPS technique is measuring daily mean sea level at PBAY with at least an accuracy of $2.3 \mathrm{~cm}$ and possibly somewhat better.

\section{CONCLUSION}

We have demonstrated that a geodetic-quality GPS unit sited close to the ocean can accurately measure sea level. The benefit of a GPS tide gauge is twofold. First, it can measure sea level in a global terrestrial reference frame and would thus be unaffected by offsets caused by earthquakes and local land subsidence. A second benefit is that the data from such a GPS unit can be used for other purposes, i.e., high-precision scientific geodesy/geophysics experiments and as a base station for surveyors. Although GPS units certainly do fail, most GPS networks operating today recover $99 \%$ of the expected data. This suggests that GPS tide gauges might be particularly useful in low-temperature areas such as Alaska and Antarctica. A true side-by-side comparison of a GPS tide gauge and a traditional tide gauge is needed to further assess the accuracy of the GPS system.

\section{APPENDIX}

Fig. 6 provides supplements for Figs. 1-3.

\section{REFERENCES}

[1] D. T. Pugh, Tides, Surges, Mean Sea-Level. Chichester, U.K.: Wiley, 1987.

[2] "Manual on Sea Level Measurement and Interpretation," IOC, Paris, France, JCOMM Tech. Rep. 31, WMO/TD. No. 1339, 2006, vol. 4, $78 \mathrm{pp}$.
[3] R. M. Heitsenrether, W. M. Hensley, and J. D. Boon, "Results from NOAA's test and evaluation of microwave radar water level sensors and plans for a transition to operational applications," in Proc. IEEE Oceans, Waikoloa, HI, 2011, pp. 1-10.

[4] B. C. Douglas, M. S. Kearney, and S. P Leatherman, Sea Level Rise: History and Consequences. San Diego, CA: Academic, 2001.

[5] J. A. Church, N. J. White, L. F. Konikow, C. M. Domingues, J. G. Cogley, E. Rignot, J. M. Gregory, M. R. van den Broeke, A. J. Monaghan, and I. Velicogna, "Revisiting the Earth's sea-level and energy budgets from 1961 to 2008," Geophys. Res. Lett., vol. 38, no. 18, p. L18 601, Sep. 2011.

[6] T. Schöne, N. Schön, and D. Thaller, "IGS tide gauge benchmark monitoring pilot project (TIGA): Scientific benefits," J. Geodesy, vol. 83, no. 3/4, pp. 249-261, Mar. 2009.

[7] G. Wöppelmann, C. Letetrel, A. Santamaria, M.-N. Bouin, X. Collilieux, Z. Altamimi, S. D. P. Williams, and B. Martin Miguez, "Rates of sea-level change over the past century in a geocentric reference frame," Geophys. Res. Lett., vol. 36, no. 12, p. L12 607, Jun. 2009.

[8] F. Soulat, M. Caparrini, O. Germain, P. Lopez-Dekker, M. Taani, and G. Ruffini, "Sea state monitoring using coastal GNSS-R," Geophys. Res. Lett., vol. 31, no. 21, p. L21 303, Nov. 2004.

[9] J. Lofgren, R. Haas, H.-G. Scherneck, and M. S. Bos, "Three months of local sea level derived from reflected GNSS signals," Radio Sci., vol. 46, no. 6, p. RS0C05, Dec. 2011.

[10] K. M. Larson, J. Löfgren, and R. Haas, "Coastal sea level measurements using a single geodetic GPS receiver," Adv. Space Res., vol. 51, no. 8, Apr. 15, 2013, to be published. [Online]. Available: http://dx.doi.org/10. 1016/j.asr.2012.04.017

[11] Y. Georgiadou and A. Kleusberg, "On carrier signal multipath effects in relative GPS positioning," Manusc. Geod., vol. 13, pp. 172-179, 1988.

[12] J.-C. Auber, A. Bibaut, and J.-M. Rigal, "Characterization of multipath on land and sea at GPS frequencies," in Proc. 7th Tech. Meet. Inst. Nav. (ION-GPS), Sept. 1994, pp. 1155-1171, part 2.

[13] M. G. G. Foreman, W. R. Crawford, J. Y. Cherniawsky, R. F. Henry, and M. R. Tarbotton, "A high-resolution assimilating tidal model for the northeast Pacific Ocean," J. Geophys. Res., vol. 105, no. C12, pp. 28629 28 651, Jan. 2000.

[14] A. T. Doodson and H. D. Warburg, Admiralty Manual of Tides. London, U.K.: HMSO, 1941.

[15] J. Ray, Z. Altamimi, X. Collilieux, and T. van Dam, "Anomalous harmonics in the spectra of GPS position estimates," GPS Solut., vol. 12, no. 1, pp. 55-64, 2008.

[16] R. D. Ray and G. D. Egbert, "The global S1 tide," J. Phys. Ocean., vol. 34, no. 8, pp. 1922-1935, Aug. 2004. 